\title{
Rancang Bangun Alat Elliptical Trainer Outdoor
}

\author{
Zainal Arifin ${ }^{1} *$, Singgih Dwi Prasetyo ${ }^{1}$, Suyitno ${ }^{1}$, Dominicus Danardono Dwi Prija Tjahjana ${ }^{1}$, \\ Rendy Adhi Rachmanto ${ }^{1}$, Wibawa Endra Juwana ${ }^{1}$, Chico Hermanu B. Apribowo ${ }^{2}$, Trismawati ${ }^{3}$ \\ ${ }^{1}$ Program Studi Teknik Mesin, Fakultas Teknik, Universitas Sebelas Maret, Indonesia \\ 2 Program Studi Teknik Elektro, Fakultas Teknik, Universitas Sebelas Maret, Indonesia \\ ${ }^{3}$ Program Studi Teknik Industri, Fakultas Teknik, Universitas Panca Marga, Probolinggo, Indonesia \\ e-mail address : zainal_arifin@staff.uns.ac.id
}

\begin{tabular}{l} 
Keywords: \\
\hline Elliptical trainer; fitness, \\
outdoor, rancang bangun; \\
Solidwork 2017a \\
\hline
\end{tabular}

\section{PENDAHULUAN}

Peralatan fitness mulai banyak diterapkan dibeberapa tempat taman wisata. Taman wisata merupakan ruang terbuka yang dapat diakses oleh masyarakat dengan berbiaya murah. Penempatan alat fitnes di taman wisata dapat dimanfaatkan sebagai penambah daya tarik wisatawan. Selain itu juga digunakan sebagai sarana sosialisasi kesehatan kepada masyarakat. Dalam hal ini masyarakat didorong untuk melakukan aktivitas fisik dengan alat fitness tersebut [1].

Alat fitness yang popular digunakan diantaranya yaitu the waist twister, air walker, ski machine, and waist/back massager [2], [3]. Air walker jenis elliptical trainer sering digunakan sebagai alat bantu berolahraga. Hal itu karena alat mempunyai resiko cedera benturan yang lebih kecil dari pada jenis lainnya. Alat digunakan berdasarkan kapasitas kecepatan latihan yang ditentukan sendiri dan tidak menyebabkan tekanan yang berlebihan pada sendi manusia. Elliptical trainer memungkinkan dirancang menggunakan program secara otomatis untuk memvariasikan kemiringan, resistensi, dan panjang langkah selama Latihan [4].

Elliptical trainer mempunyai prinsip kerja seperti orang berjalan dimana tubuh bergerak dipengaruhi oleh gaya tekan tangan dan pergerakan kaki [5]. Elliptical trainer terutama digerakkan oleh kaki pengguna, dan sebagian besar adalah kombinasi dengan tuas pegangan yang melekat pada pedal link yang dibebankan pada lengan sebagai sumber sekunder daya penggerak. Karenanya gerakan pegangan berosilasi dan terkoordinasi yang bergantung pada gerakan pedal dan tuas pegangan [6].

Alat elliptical trainer mempunyai bentuk yang berbeda-beda menyesuaikan fungsi dan keadaan lingkungan alat saat digunakan. Semakin banyak fungsi yang diinginkan mempengaruhi kerumitan dalam fabrikasi kerangka. Faktor lingkungan sekitar saat alat digunakan akan mempengaruhi daya tahan cuaca dan faktor keamanan alat [7], [3]. Apabila diletakkan di tempat outdoor seperti taman wisata, alat jenis elliptical trainer perlu 
dilakukan rancang bangun ulang agar dapat berfungsi dalam kondisi cuaca dan pemakaian luar ruangan.

Berdasarkan pengertian dan permasalahan yang telah dipaparkan, sangat menarik apabila alat elliptical trainer dapat ditempatkan pada tempat wisata yang ada di wilayah Jawa, Indonesia. Maka dari itu, artikel ini lebih memfokuskan membahas tentang proses rancang bangun alat elliptical trainer outdoor. Rancang bangun dilakukan dengan mengutamakan nilai faktor keamanan berdasarkan berat badan orang Indonesia pada umumnya.

\section{METODOLOGI PENELITIAN}

Action Research dilakukan pada metode penelitian ini. Pada metode penelitian tindakan ini peneliti melakukan penerapan bidang ilmu yang sesuai dengan konsep rekayasa rancang bangun yang dilakukan [8]. Perancangan dilakukan menggunakan aplikasi Solidwork 2017a. Proses manufaktur alat dilakukan di Laboratorium Teknik Mesin Universitas Sebelas Maret. Secara umum langkah rancang bangun yang dilakukan terlihat pada Gambar 1.

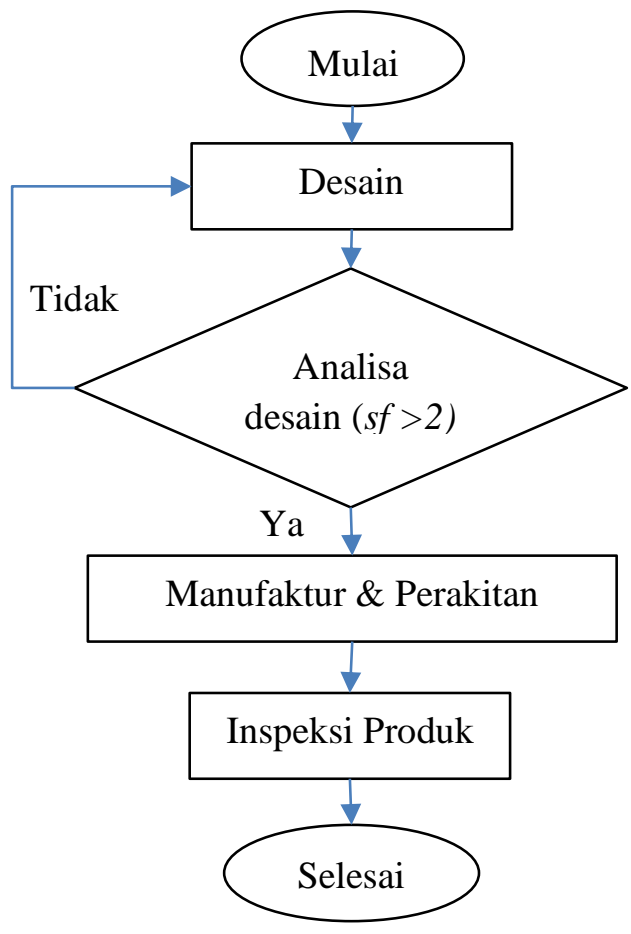

Gambar 1. Alur rancang bangun alat elliptical trainer

\subsection{Desain}

Alat elliptical trainer dibagi menjadi beberapa bagian yaitu rangka utama, penggerak, handle dan bagian pijakan kaki. Desain dilakukan menggunakan aplikasi Solidwork 2017a. Bentuk setiap bagian disesuaikan dengan nilai beban yang akan diberikan sebesar $150 \mathrm{~kg}$. Pembuatan desain diharuskan mempunyai nilai faktor keamanan $(s f)$ lebih dari 2 [9]. Pemilihan material berdasarkan pendekatan harga, kekuatan dan ketersediaan. Semua bagian utama rancangan didesain menggunakan material galvanized steel yang tersedia di kota Surakarta, Indonesia [10].

\subsection{Analisa Desain}

Analisa desain dilakukan untuk mengetahui nilai kekuatan dan keamanan alat elliptical trainer sebelum dilakukan manufaktur. Nilai kemanan atau faktor keamanan (sf) diketahui dari analisa static pada desain. Faktor keamanan dapat ditentukan untuk desain yang jenis materialnya sudah diketahui terhadap tegangan luluh pada kondisi lingkungan dan beban mempunyai nilai standar sebesar 1,5-2 [11]. Sehingga diharapkan desain mempunyai nilai keamanan lebih dari standar yang ada.

\subsection{Manufaktur dan perakitan}

Proses manufaktur dilakukan untuk membuat bagian yang sudah didesain sesuai fungsinya. Dalam hal ini, proses manufaktur dikhususkan untuk bagian yang tidak dapat dibeli dipasaran atau perlu direkayasa. Manufaktur diklasifikasikan berdasarkan perlakuan terhadap material untuk membentuk satu produk utuh sesuai dengan Design for manufacture and assembly dan permesinan [12]. Proses perakitan dilakukan untuk menyatukan setiap bagian menjadi satu produk alat fitness berupa outdoor elliptical trainer. Setiap bagian dirakit sesuai dengan bentuk dan perlakuan yang dibutuhkan, sehingga dapat menyatu dalam satu kesatuan alat fitness yang kompak dan kuat [13]. 


\subsection{Inspeksi Produk}

Alat elliptical trainer outdoor yang telah berhasil dirakit, sebelum digunakan dilakukan uji coba pemakaian. Selain itu, inspeksi untuk setiap sambungan diakukan secara visual oleh peneliti [14].

\section{HASIL DAN PEMBAHASAN}

\subsection{Desain}

Pembuatan desain 3D alat elliptical trainer outdoor secara keseluruhan telah berhasil

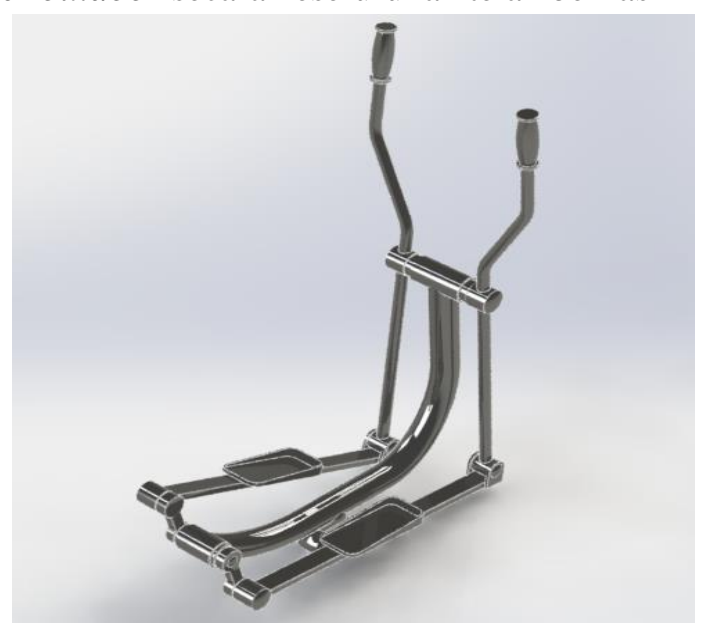

dilakukan, sebagaimana terlihat pada Gambar 2 . Desain alat menggunakan konsep pendekatan alat yang telah ada dipasaran. Penyesuaian desain dilakukan untuk mempertimbangkan kapasitas dan fungsional alat. Kapasitas alat ditujukan untuk orang dewasa dengan berat maksimum 150 $\mathrm{kg}$. Sedangkan fungsional alat didesain agar saat pemakaian nyaman digunakan oleh kalangan masyarakat. Desain alat terdiri dari 4-bagian utama yaitu rangka utama, poros penggerak, handle tangan, dan handle kaki. Rangka utama difokuskan menjadi titik beban alat pada desain ini. Material bagian utama untuk manufaktur didesain menggunakan besi galvanis.

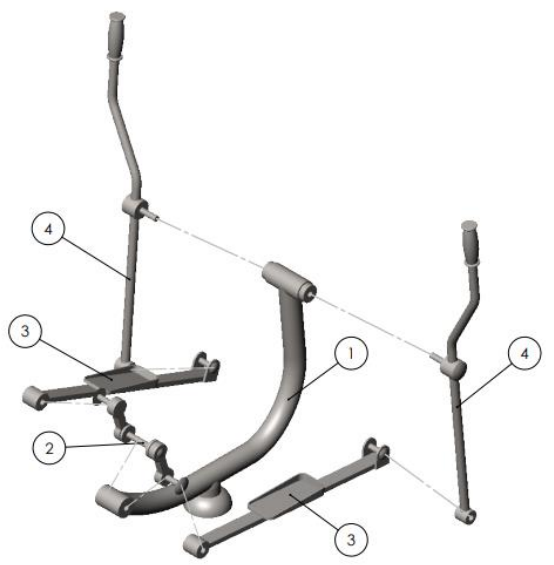

Gambar 2. Desain 3D alat elliptical trainer outdoor

Gambar 3a merupakan desain 3D bagian rangka utama alat elliptical trainer. Rangka utama menjadi penompang dari bagian lainnya. Sehingga struktur bagian ini dibuat sekuat mungkin. Gambar 3b merupakan desain 3D bagian poros penggerak alat elliptical trainer. Bagian ini berfungsi sebagai poros penghubung antar bagian. Dalam bagian ini dilengkapi bearing agar setiap bagian lainnya dapat bergerak secara dinamis [7]. Gambar 3c merupakan bagian handle tangan alat elliptical trainer. Bagian ini berfungsi sebagai pegangan saat alat dioperasikan. Desain dibuat senyaman mungkin pada tuas tangan. Tuas tangan memiliki kontur yang sesuai dengan genggaman, tidak kasar, dan tidak licin [15]. Gambar 3d merupakan bagian handle kaki alat elliptical trainer. Bagian ini berfungsi sebagai pijakan kaki dan pendorong poros saat alat dioperasikan. Pijakan dibuat menyerupai bentuk kaki manusia [16]. 


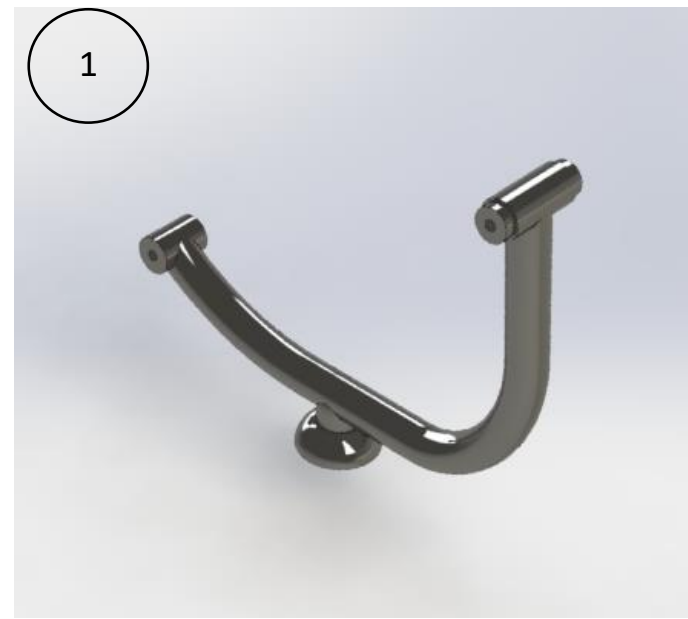

(a)

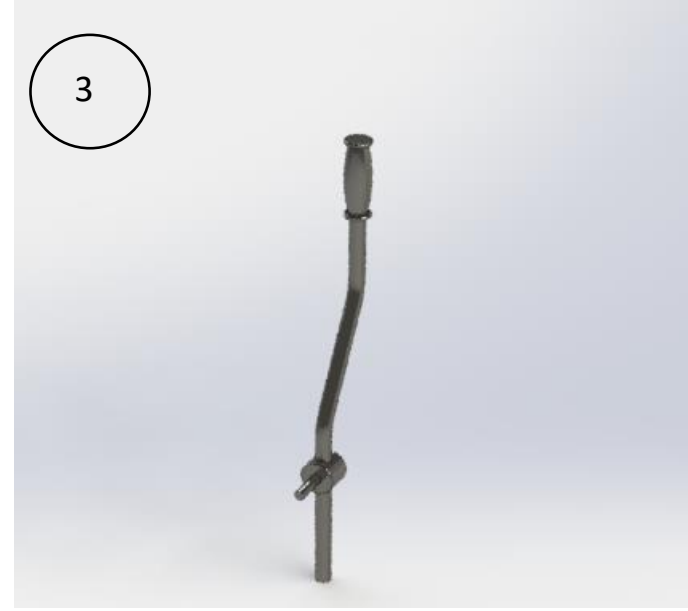

(c)

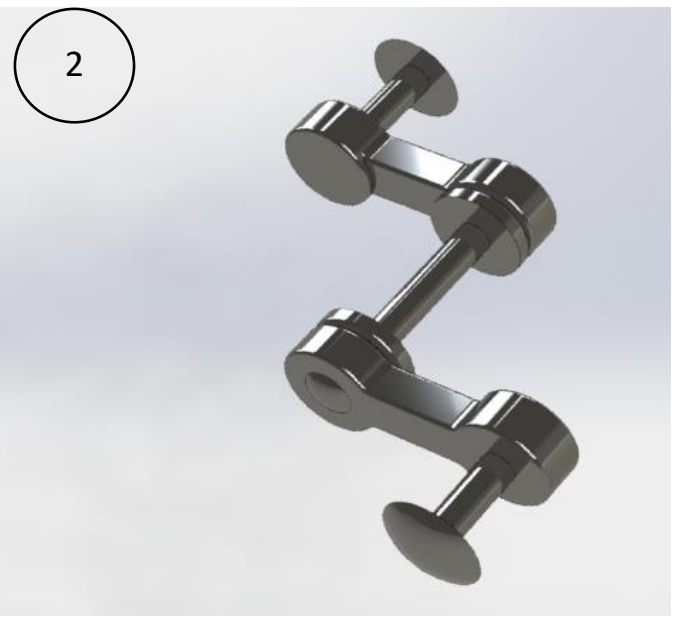

(b)

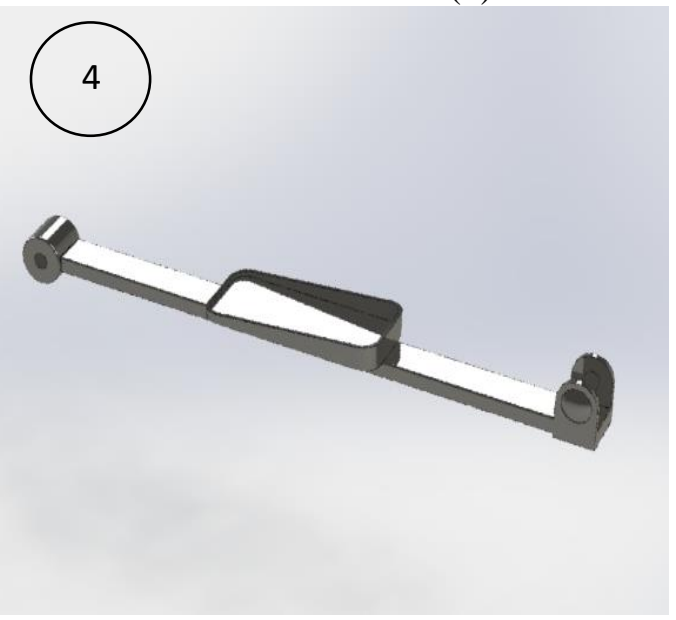

(d)

Gambar 3. Desain 3D bagian (a) rangka utama (b) poros penggerak (c) handle tangan (d) handle kaki

Alat elliptical trainer didesain dengan dimensi berukuran 2500 x $1800 \times 1000 \mathrm{~mm}$. Ukuran desain untuk setiap bagian disesuaikan dengan nilai kekuatan yang diinginkan. Dimana ukuran bagian rangka utama didesain lebih besar dibandingkan daripada bagian lainnya.
Sedangkan ukuran bagian lainya menyesuaikan dengan kebutuhan. Ukuran dimensi setiap bagian dapat dilihat pada Gambar 4 dengan satuan mm, penentuan ukuran dimensi digunakan untuk mempermudah dan menghemat pembelian material [17]. 


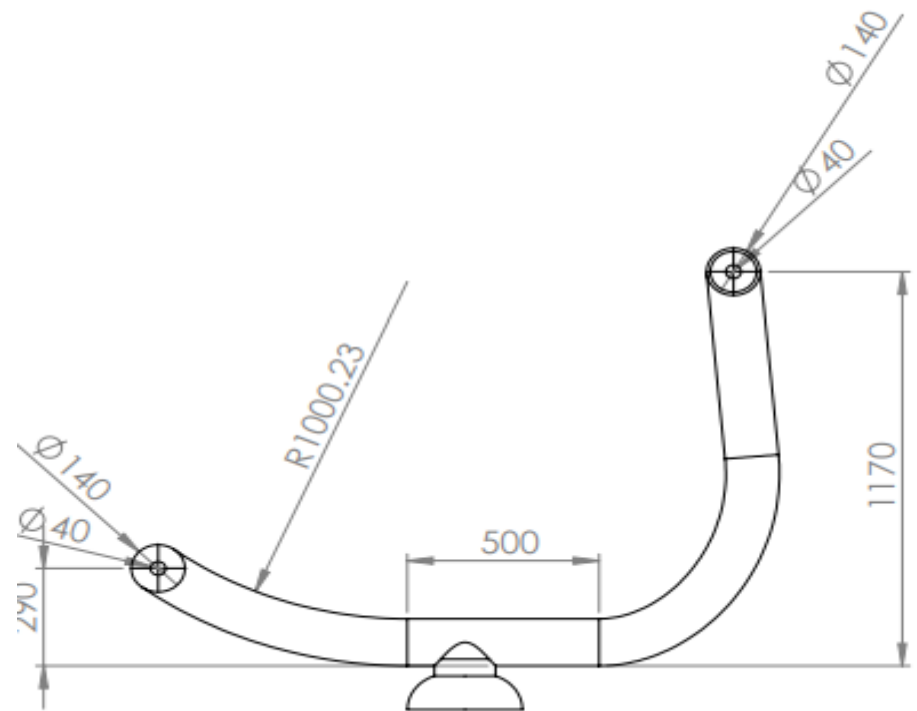

(a)

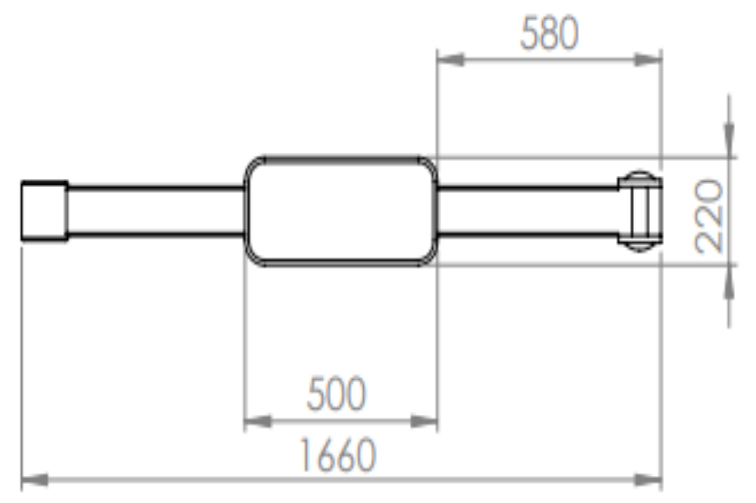

(c)

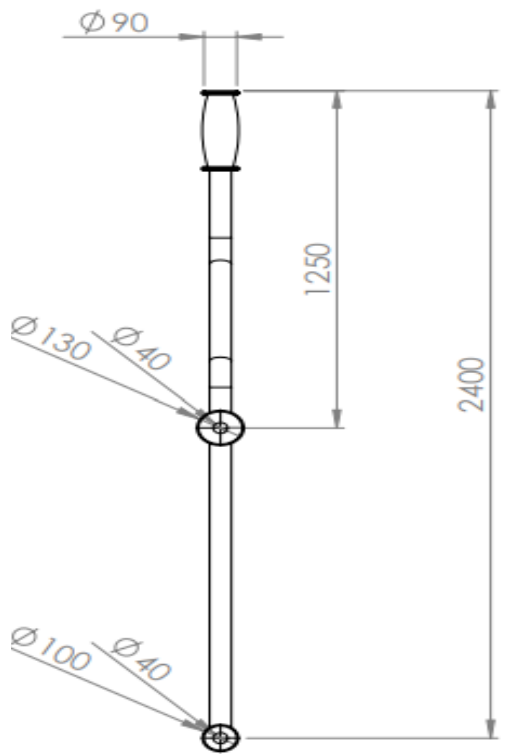

(b)

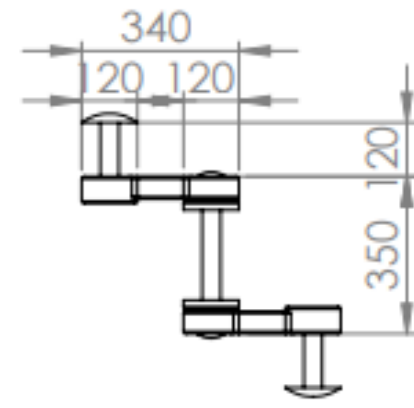

(d)

Gambar 4. Desain 2D Bagian (a) rangka utama (b) handle tangan (c) handle kaki (d) poros penggerak

\subsection{Analisa Desain}

Bagian rangka utama dilakukan analisa desain dengan simulasi statik menggunakan Solidwork 2017a. Simulasi rangka utama digunakan sebagai pedoman nilai kekuatan desain untuk bisa dilakukan manufaktur. Rangka utama berperan sebagai penopang beban. Simulasi statik dilakukan dengan memberikan beban pada titik kritis sambungan setiap bagian. Beban dilakukan secara merata pada titik pertemuan antar bagian yang akan disambung sebesar $150 \mathrm{~kg}$ sesuai dengan kriteria pemakai alat dan meshing desain dengan ukuran $24 \mathrm{~mm}$. Properti yang digunakan dalam simulasi statik dapat dilihat pada Tabel 1. Dapat diketahui bahwa, desain kerangka utama mempunyai faktor keamanan sebesar 3. Tingginya faktor keamanan menjadi pedoman bahwa pemilihan material besi galvanis dapat digunakan dalam perancangan dan memiliki kekuatan yang baik. Hal itu ditandai dengan desain mempunyai displacement yang kecil sebesar $8.524 \mathrm{e}^{-7} \mathrm{~mm}$ sebagaimana terlihat Gambar 5. 
Tabel 1. Properties Analisa Statik

\begin{tabular}{|l|c|}
\hline Model Reference & Properties \\
\hline Name: $\quad$ Galvanized Steel \\
Model type: $\quad$ Linear Elastic Isotropic \\
Default failure $\quad$ Max von Mises Stress \\
criterion:
\end{tabular}

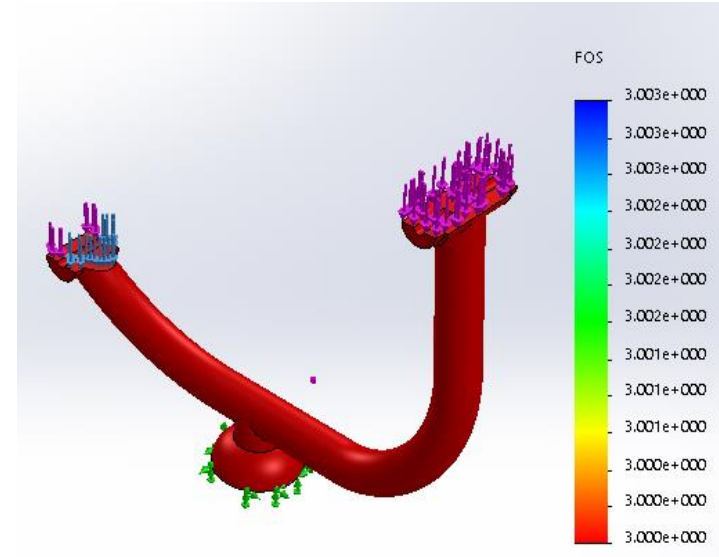

(a)

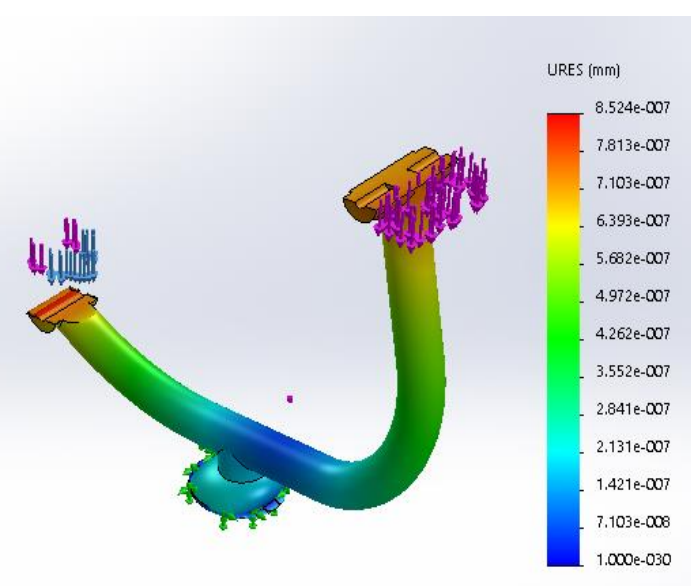

(b)

Gambar 5. (a) Hasil Simulasi Statik Faktor keamanan (b) Hasil Simulasi Displacement

\subsection{Manufaktur dan Perakitan}

Proses manufaktur alat elliptical trainer telah berhasil dilakukan menggunakan metode Design for Manufactur and Assembly (DFMA) dan rancangan permesinan. Penggunaan DFMA untuk mengetahui kelemahan, perlakuan, kuantitas, dan alat manufaktur. Sehingga dapat mengurangi resiko gagal manufaktur dan mempermudah dalam pengerjaan [18]. Proses manufaktur pada alat elliptical trainer dapat dilihat pada Tabel 2 dan Tabel 3. Dimana material dibentuk sedemikian rupa sehingga menjadi suatu produk jadi.. 
Tabel 2. DFMA alat elliptical trainer

\begin{tabular}{|c|c|c|c|c|c|c|c|c|c|c|c|c|c|c|c|c|c|c|}
\hline & Bagian & $\begin{array}{r}D \\
C o n\end{array}$ & & $\begin{array}{r}\text { Fun } \\
A n\end{array}$ & & $\begin{array}{l}\text { Error } \\
\text { Proofi } \\
\text { ng }\end{array}$ & & ndli & & & nser & tion & & & Con & th & & \\
\hline 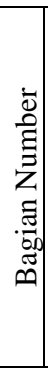 & Gambar Assembly & 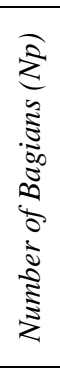 & 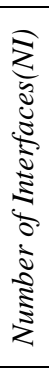 & 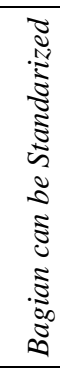 & 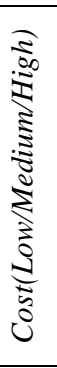 & 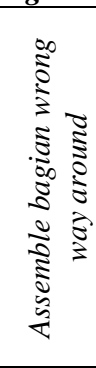 & 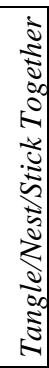 & 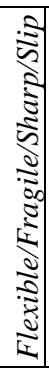 & 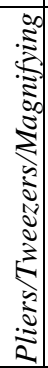 & $\begin{array}{l}0 \\
0 \\
0 \\
\vdots \\
0 \\
0 \\
0 \\
0 \\
0 \\
0 \\
0 \\
0 \\
0 \\
0\end{array}$ & 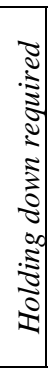 & 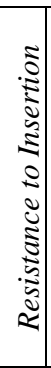 & 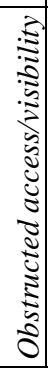 & 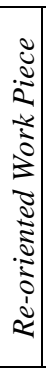 & 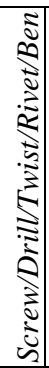 & 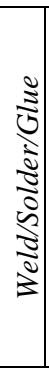 & 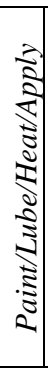 & 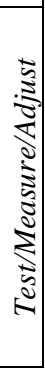 \\
\hline 1 & Rangka Utama & 1 & 1 & $\mathrm{~N}$ & $\mathrm{H}$ & $\mathrm{Y}$ & $\mathrm{N}$ & $\mathrm{N}$ & $\mathrm{N}$ & Y & $\mathrm{Y}$ & $\mathrm{N}$ & $\mathrm{N}$ & $\mathrm{Y}$ & $\mathrm{Y}$ & $\mathrm{Y}$ & Y & Y \\
\hline 2 & Poros Penggerak & 2 & 2 & Y & $\mathrm{L}$ & $\mathrm{N}$ & $\mathrm{T}$ & $\mathrm{N}$ & $\mathrm{N}$ & Y & $\mathrm{N}$ & $\mathrm{N}$ & $\mathrm{N}$ & $\mathrm{Y}$ & $\mathrm{N}$ & Y & $\mathrm{Y}$ & $\mathrm{N}$ \\
\hline 3 & Handle Kaki & 2 & 2 & $\mathrm{~N}$ & $\mathrm{~L}$ & $\mathrm{Y}$ & S & $\mathrm{N}$ & $\mathrm{N}$ & $\mathrm{Y}$ & $\mathrm{Y}$ & $\mathrm{N}$ & $\mathrm{N}$ & $\mathrm{Y}$ & Y & Y & Y & $\mathrm{N}$ \\
\hline 4 & Handle Tangan & 2 & 2 & $\mathrm{~N}$ & M & Y & $S$ & $\mathrm{~N}$ & $\mathrm{~N}$ & Y & Y & $\mathrm{N}$ & $\mathrm{N}$ & Y & $\mathrm{Y}$ & $\mathrm{Y}$ & Y & $\mathrm{Y}$ \\
\hline 5 & Pasak & 2 & 2 & $\mathrm{Y}$ & $\mathrm{L}$ & Y & $\mathrm{T}$ & $\mathrm{N}$ & $\mathrm{N}$ & $\mathrm{N}$ & $\mathrm{N}$ & $\mathrm{N}$ & $\mathrm{N}$ & Y & $\mathrm{Y}$ & $\mathrm{N}$ & Y & $\mathrm{N}$ \\
\hline 6 & Ring & 4 & 4 & $\mathrm{Y}$ & $\mathrm{M}$ & $\mathrm{N}$ & $\mathrm{T}$ & $\mathrm{N}$ & $\mathrm{N}$ & $\mathrm{N}$ & $\mathrm{N}$ & $\mathrm{N}$ & $\mathrm{N}$ & $\mathrm{N}$ & $\mathrm{Y}$ & $\mathrm{N}$ & Y & $\mathrm{N}$ \\
\hline 7 & Bearing & 4 & 4 & Y & $\mathrm{L}$ & $\mathrm{N}$ & $\mathrm{T}$ & $\mathrm{N}$ & $\mathrm{N}$ & Y & $\mathrm{N}$ & $\mathrm{N}$ & $\mathrm{N}$ & $\mathrm{N}$ & $\mathrm{N}$ & $\mathrm{N}$ & Y & $\mathrm{N}$ \\
\hline
\end{tabular}

Tabel 3. Permesinan alat elliptical trainer

\begin{tabular}{|c|c|c|c|c|c|c|c|c|c|c|}
\hline $\begin{array}{l}\text { Nomor } \\
\text { Bagian }\end{array}$ & Nama Bagian & $\begin{array}{c}\text { Tappi } \\
\text { ng }\end{array}$ & $\begin{array}{l}\text { Counterbo } \\
\text { ring }\end{array}$ & $\begin{array}{c}\text { Drilli } \\
n g\end{array}$ & $\begin{array}{c}\text { Milli } \\
\text { ng }\end{array}$ & $\begin{array}{c}\text { Grindi } \\
\quad n g \\
\end{array}$ & $\begin{array}{c}\text { Shapi } \\
\text { ng }\end{array}$ & $\begin{array}{c}\text { Fill } \\
\text { et }\end{array}$ & $\begin{array}{c}\text { Cham } \\
\text { fer }\end{array}$ & Other \\
\hline 1 & Rangka Utama & M14 & $\mathrm{N}$ & 13 & $\mathrm{~N}$ & $\mathrm{Y}$ & $\mathrm{N}$ & $\mathrm{N}$ & $\mathrm{Y}$ & \\
\hline 2 & $\begin{array}{l}\text { Poros } \\
\text { Penggerak }\end{array}$ & M14 & $\mathrm{N}$ & 22 & $\mathrm{~N}$ & $\mathrm{Y}$ & $\mathrm{N}$ & $\mathrm{N}$ & $\mathrm{Y}$ & \\
\hline 3 & Pijakan Kaki & M14 & $\mathrm{N}$ & 20 & $\mathrm{~N}$ & $\mathrm{Y}$ & $\mathrm{N}$ & $\mathrm{N}$ & Y & \\
\hline 4 & $\begin{array}{l}\text { Handle } \\
\text { Tangan }\end{array}$ & M14 & $\mathrm{N}$ & 22 & $\mathrm{~N}$ & $\mathrm{Y}$ & $\mathrm{N}$ & $\mathrm{N}$ & $\mathrm{Y}$ & \\
\hline 5 & Pasak & M14 & $\mathrm{Y}$ & 20 & $\mathrm{~N}$ & $\mathrm{Y}$ & $\mathrm{Y}$ & $\mathrm{N}$ & $\mathrm{Y}$ & \\
\hline 6 & Ring & & & & & & & & & $\begin{array}{l}\text { Purch } \\
\text { ased }\end{array}$ \\
\hline 7 & Bearing & & & & & & & & & $\begin{array}{l}\text { Purch } \\
\text { ased }\end{array}$ \\
\hline
\end{tabular}

Setelah dilakukan proses manufaktur pada setiap komponennya. Dilakukan perakitan dengan melakukan penyambungan untuk setiap bagian komponen menjadi satu buah produk [19]. Penyambungan dilakukan menggunakan las listrik. Setiap komponen bagian disatukan menggunakan sambungan butt joint, edge joint, dan $t$ joint. Sambungan las digunakan pada setiap komponen karena mempunyai titik paling kuat daripada material utamanya dan lebih mudah untuk penyambungan pipa. Sehingga hasil las harus rata dan tidak berlubang [20].

Proses finishing pada rancang bangun alat elliptical trainer dilakukan dengan memberikan cairan anti karat Rexco 50 ke seluruh komponen. Hal ini bertujuan untuk melindungi besi dari karat karena perubahan cuaca di luar ruangan. Pembersihan komponen dari debu atau tanah yang masih menempel dilakukan sebelum pemberian cairan anti karat. Setelah itu dilakukan proses pewarnaan agar berkesan mengkilap dan bernilai estetik. Saat peletakan di luar ruangan untuk melindungi dari goresan benda lain, alat elliptical trainer dilakukan pelapisan bening (clear). 


\subsection{Inspeksi Produk}

Hasil manufaktur dilakukan inspeksi pada setiap sambungan las. Inspeksi untuk mengetahui cacat retak pada las secara visual. Gambar 6a mewakili setiap bagian penyambungan yang menunjukan tidak adanya cacat las. Alat elliptical trainer dipasang di tempat terbuka

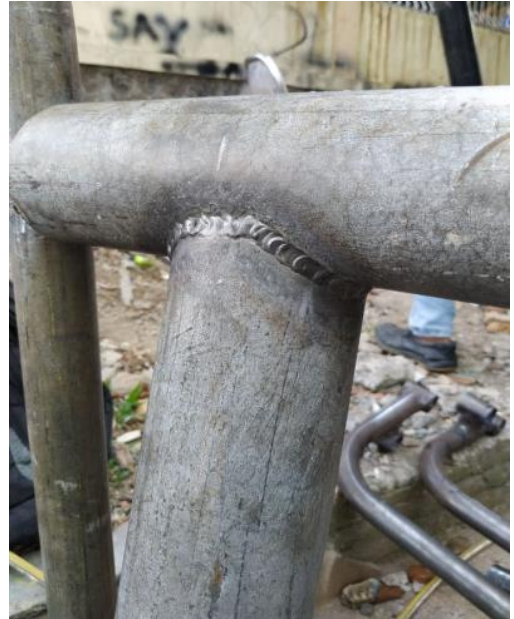

(a) sebagai sarana masyarakat untuk berolah raga, sehingga perlu dipastikan faktor keamanannya. Hasil pengujian menunjukkan alat dapat beroperasi dengan baik dan aman, seperti dapat dilihat pada Gambar 6b. Rancang Bangun alat elliptical trainer diketahui memiliki harga manufaktur yang lebih murah $10 \%$ dibandingkan dengan harga alat yang ada dipasaran.

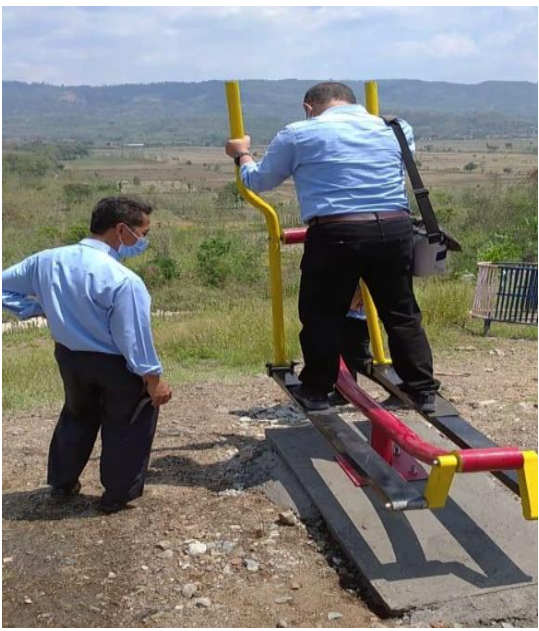

(b)

Gambar 6. (a) Inspeksi sambungan las (b) Trial fungsional Alat elliptical trainer

\section{KESIMPULAN}

Manufaktur alat elliptical trainer telah berhasil dilakukan. Alat elliptical trainer dengan dimensi $2500 \mathrm{~mm}$ x $1800 \mathrm{~mm}$ x $1000 \mathrm{~mm}$ didesain menggunakan aplikasi Solidwork 2017a. Desain alat dilakukan untuk empat bagian utama yaitu bagian rangka utama, poros penggerak, pegangan tangan, dan pinjakan kaki. Dengan pembebanan maksimum kapasitas manusia sebesar $150 \mathrm{~kg}$, rangka utama memiliki nilai faktor keamanan desain sebesar 3 dengan displacement sebesar $8.524 \mathrm{e}-7 \mathrm{~mm}$ yang menandakan kekuatan alat. Setiap bagian telah berhasil dilakukan proses manufaktur dan perakitan sesuai dengan Design Manufacture and Assembly (DFMA) dan perencanaan permesinan. Hasil inspeksi secara visual tidak terlihat adanya cacat las pada setiap sambungan. Proses finishing menggunakan cat luar anti karat dengan penambahan perlakuan anti gores atau clear membantu alat elliptical trainer bertahan di kondisi cuaca luar ruangan.

\section{PERNYATAAN TERIMAKASIH}

Penulis mengucapkan terima kasih kepada Rektor Universitas Sebelas Maret atas Skema Hibah Pengabdian Group Riset Dana PNBP dengan kontrak No: 453/UN27.21/PN/2020 dan Pemerintah Desa Karangasem dalam mendukung Program Pengabdian kepada Masyarakat UNS Tahun 2020.

\section{REFERENSI}

[1] H. W. Chow and D. R. Wu, "Outdoor fitness equipment usage behaviors in natural settings," International Journal of Environmental Research and Public Health, vol. 16, no. 3, 2019.

[2] E. M. Medica et al., "The Journal of Sports Medicine and Physical Fitness This provisional PDF corresponds to the article as it appeared upon acceptance . Outdoor physical activity bears multiple benefits to health and society COPYRIGHT () EDIZIONI MINERVA MEDICA Outdoor physic," 2019.

[3] O. Article, "A Comparison of the Aerobic Cost in Aerobic Dance to the Energy Costs on Treadmill, Elliptical Trainer, and Bicycle 
Ergometry Hahn R, Kaethler R, Poblete D, Matsuda G, Wong M," vol. 2, no. 6, pp. 1220, 2013.

[4] B. P. Wallace, "Comparing energy expenditure between the treadmill and elliptical trainer," 2005.

[5] W. Choi, A. Song, D. Edge, M. Fukumoto, and U. Lee, "Exploring user experiences of active workstations: A case study of under desk elliptical trainers," UbiComp 2016 Proceedings of the 2016 ACM International Joint Conference on Pervasive and Ubiquitous Computing. pp. 805-816, 2016.

[6] F. C. Chen, Y. F. Tzeng, and M. H. Hsu, "Innovative design of an elliptical trainer with right timing of the foot trajectory," Advances in Technology Innovation, vol. 5, no. 3, pp. 190-201, 2020.

[7] J. M. Burnfield, Y. Shu, T. W. Buster, P. Adam, and C. A. Nelson, "Technical Report Impact of Elliptical Trainer Ergonomic Usability for People With Physical," 2011, doi: $10.2522 / \mathrm{ptj} .20100332$.

[8] A. Roziqin, "Peningkatan Kemampuan Mahasiswa Menggunakan Metode Project Based ( Improvement of Students ' Ability Using Project Based Competition Method," Jurnal Pendidikan Teknik Mesin, vol. 17, no. 2, pp. 57-61, 2017.

[9] I. Sungkono, H. Irawan, and D. A. Patriawan, "Analisis Desain Rangka Dan Penggerak Alat Pembulat Adonan Kosmetik Sistem Putaran Eksentrik Menggunakan Solidwork," pp. 575-580, 1995.

[10] R. Ratnayanti, M. Nugraha, and F. Yustiana, "Analisis Pemilihan Alternatif Material Pada Pembanguan Bendung (Studi Kasus Pembangunan Bendung Aporo-Sulawesi Tenggara)," Jurnal Teknik Sipil ITENAS, vol. 5, no. 1, p. 10, 2007.

[11] Z. Arifin, S. D. Prasetyo, T. Triyono, C. Harsito, and E. Yuniastuti, "Rancang Bangun
Mesin Pencacah Limbah Kotoran Sapi," Jurnal Rekayasa Mesin, vol. 11, no. 2, pp. 187-197, 2020.

[12] L. Marxen et al., "Concurrent engineering and DFMA/DFX in the development of automotive components," Procedia CIRP, vol. 41, no. May, pp. 241-260, 2001.

[13] A. Efendi, "Rancang Bangun Mobil Listrik Sula Politeknik Negeri Subang," Jurnal Pendidikan Teknologi dan Kejuruan, vol. 17, no. 1 , p. $75,2020$.

[14] I. Djodikusumo and D. Arisandi, "Desain , Manufaktur, dan Inspeksi Produk Berbasis Fitur," no. Snttm Xiv, pp. 7-8, 2015.

[15] L. Widyokusumo, "Teknik Arsir dan Proses Menggambar dengan Media Pena," Humaniora, vol. 5, no. 2, p. 909, 2014.

[16] D. Herawati, "Kaki Manusia Sebagai Objek Estetik Penciptaan Fotografi Seni," REKAM: Jurnal Fotografi, Televisi, dan Animasi, vol. 10, no. 1, pp. 19-37, 2014

[17] D. Bertol, "Designing and Making a Movement Infrastructure," Procedia Technology, vol. 20, no. July, pp. 72-78, 2015.

[18] C. Yin and S. Hou, "Application design for manufacture and assembly to improving product design and development performance," 2019 ASABE Annual International Meeting, pp. 1-9, 2019.

[19] Industry Xplore and M. Sayuti, "Perbaikan Proses Perakitan case Assembly Front With Water Pump And Oil Pump Pada Perusahaan Automotive Di Karawang," Industry Xplore, vol. 5, no. 1, pp. 1-7, 2020.

[20] R. Rinaldi, R. Usman, A. Fathier, J. Teknik, M. Politeknik, and N. Lhokseumawe, "Studi eksperimental kekuatan tarik dan kekerasan pada sambungan pipa ASTM A 106 Grade B dengan pengelasan SMAW," vol. 1, no. 2, pp. 36-42, 2019. 